\title{
Labyrinthe
}

32 | 2009 (1)

Le petit théâtre intellectuel

\section{La Pythie}

\section{Laurent Dubreuil}

\section{(2) OpenEdition}

Journals

Édition électronique

URL : http://journals.openedition.org/labyrinthe/3988

DOI : 10.4000/labyrinthe.3988

ISSN : 1950-6031

Éditeur

Hermann

Édition imprimée

Date de publication : 19 juin 2009

Pagination : 53-54

ISBN : 978-2-7056-6885-3

Référence électronique

Laurent Dubreuil, « La Pythie », Labyrinthe [En ligne], 32 | 2009 (1), mis en ligne le 01 février 2011,

consulté le 22 avril 2019. URL : http://journals.openedition.org/labyrinthe/3988 ; DOI : 10.4000/ labyrinthe.3988

Propriété intellectuelle 


\section{Le petit théâtre intellectuel}

\section{LA PYTHIE}

Divine elle devine, sa bouche d'ombre s'ouvre, qui parle de ce qui se passera, de ce qui est. La Pythie a l'habitude du haut verbe; raison pour laquelle il lui faut avant l'oracle se mettre au-dessus des autres, monter sur quelque trépied - chaire professorale, autorité d'artiste, prestige de l'ancienneté, sublimité du style, ou tout cela ensemble. La Pythie s'exprime, beaucoup nient, d'aucuns l'ignorent, certains déduisent. Puis elle se tait. On se montre Pythie le temps d'une crise. Il faut de la concentration, de l'expérience, de l'inspiration, après quoi la parole retombe, fracassante, ou inopérante. Quoique l'on se puisse montrer expert en prophétie, nul n'est Pythie à temps complet, ce serait trop galvauder l'effet. Ce pythique caractère, plus qu'aucun encore peut-être, est destiné à s'accomplir fort différemment, selon la qualité des comédiens et des actrices. Pis, en un sens, « la » Pythie c'est vite dit, car j'en connais plus d'une.

Benoîte par exemple jouit d'une vraie célébrité dans la famille. Grâce à ses yeux perçants, elle discerne le radieux avenir que votre myopie et vos lunettes noires vous empêchent de voir. Elle vous le promet, Benoîte, tout finit toujours par s'arranger, les conflits disparaîtront, le bonheur sera attribué, n'en doutez point. Grands enfants, nous voudrions toujours l'aimer, notre chère Benoîte: elle fait penser à ces professeurs rassurants par qui nous prenions foi dans notre propre futur. Hélas, elle a parfois perdu de sa réputation; son intégrité ne convainc plus. Comme la fois où son impartial éloge de la modernité technique s'est transformé en spot publicitaire. Et en général tous les moments, où, semble-t-il, un peu d'argent donné par la bonne main favorisa l'idoine prédiction.

La Momie sa cousine n'a pas de ces difficultés. Elle a arrêté la pratique des vapeurs enthousiasmantes, elle s'en tient plutôt à l'extrapolation depuis sa lon-ongue expérience. «Du nouveau, ceci? nenni, l'affaire se rencontrait déjà en 1922, pendant la Révolution, chez les Étrusques. » Comme la Momie n'a plus d'âge, son récit de l'Antiquité gréco-romaine prend des allures d'autobiographie. Et notre aujourd'hui, et le jour d'après, conditionnés, contenus par autrefois, se trouvaient déjà préfigurés dans les événements écoulés. Merveille! les Centuries de la Momie sont une 
chronique de l'ancien temps, mise au futur pour faire joli. Annonceraitelle une catastrophe, la Momie n'en serait pas moins consolatrice à sa façon. Si l'histoire se répète, l'horreur ne sera que transitoire; et au pire nous resteront les leçons à tirer.

Cassandre, elle, n'est pas de cet avis. Désolé, mais pour elle, le parler pythie ne servira pas à la consolation. À la rigueur, nous pourrions goûter la véracité de l'oracle, mais étant donné ce qu'il recèle, nous n'aurions guère le temps de profiter d'un pareil succès. Car demain il fera nuit. La destruction est aux portes. Même, n'est-elle pas déjà bien avancée? Nous vivons la fin du livre, de la pensée, de l'amour, de l'art, de la vie; et l'agonie commence à peine. Il arrive que Cassandre soit un peu Momie aussi, l'aigreur ajoutée: nous éprouvons « la permanence dans la catastrophe », avec l'obstination de l'apocalypse, les images atroces du passé ne seront plus que recyclées par notre gâtisme contemporain. Toujours survivante d'un état révolu, Cassandre n'est pas pour autant vouée à jouer le Témoin sénescent. Elle est également à la mode, voire rock star annonçant l'indépassable nullité de notre année zéro.

Les Pythies ne s'accordent donc pas entre elles, et le soleil comme la ténèbre pourraient bientôt paraître au carreau. Malgré son brio, la Pythie s'apparente à Madame Irma, la fameuse voyante inconnue (comme il est de tels soldats) et qui ne se trompe pas moins d'une fois sur deux. La Pythie nous promit la disparition de la poésie, l'heureuse suspension de l'histoire dans la paix capitaliste, la société sans classe, la victoire de l'intelligence collective sur Internet, la santé désormais inaltérable des marchés financiers, la fin du travail, nous attendons toujours. À l'époque hellénistique, Plutarque s'interrogeait sur les raisons du déclin des oracles, et en particulier le récent manque de fiabilité dans les mots de la Pythie. Est-ce que pour nous à notre tour, le Grand Pan est mort? «- Bien sûr que non, le futur néo-techno guérira la moindre plaie de l'âme, répond Benoîte. - Vous voyez bien que ce n'est pas la première fois, précise la Momie. - Sauf que nous n'aurons plus sous peu les moyens de vérifier notre propre décadence, rétorque Cassandre. » Sur ce, silence gêné.

L. D.

\section{Bibliographie, références, lecture}

I. Plutarque, Sur les oracles de la Pythie (De Pythiae oraculis), texte établi et traduit par R. Flacelière, Paris, Belles-Lettres, 2007. 